unlike what exists in most diseases, is unable to give an account of the invasion of the disease, of the variance in his batits of life from the normal, to account for this serious change in his condition and state,-in fact, in most cases, the urincipal actor in what has caused the disease is by the disease frevented from giving any information about it. This is a serious obstacle to research as to the causation of insanitr, and it entails a necessity for greater and more cureful iuvestigation from collateral sources.

Te know that old writers ascribe the absence of epilepsy in aucient days in Scotland to the castration in youth of all the males who took fits, and that by this the propagation of the disease was stopped. This treatment, though rough and against the sentiment of the present time, was no doubt efficacious. The shutting up in asylums of those who labour under mental disease to such an extent as not to be able to take eare of themselves-weak-minded, erotic, and epileptic girls and youths-must undoubtedly stop what would be almost inevitable in these cases, the procreation of a nervously diseased set of illegitimate children. Even within the last thirty years or so was it the case that silly, weakminded, or idiotic females, in whom the physique was at all developed, fell an easy prey to any seducer, and were often the parents of a succession of children, many of whom, if not all, were likely to be imbecile-at any rate, if they escaped at birth, far more likely than those of healthy descent to be affected by nervous disease at the critical periods of life. The present asylum system to a certain extent provides against this in eases which manifestly are quite unfit to be at large ; but there are many of the class I allude to at large, spreading the mischief. So much for the prevention by transmission by those clearly insane or markedly weak-minded.

(To be concluded.)

\section{REMOVAL OF THE RIGHT LOBE OF THE THYROID.}

BY F. A. PURCELL, M.D.,

SURGEOX TO THE CANCER HOSPITAL, BROMPTON.

SARAH S. R- single, aged twenty-three, a strawplatter, from Dunstable. About three years and a half ago this girl noticed a slight enlargement in her neck, most towards the right side. Since then it has been steadily increasing, giving no pain. General health good. Catamenial discharge regular. She knows other women in the neighbourhood who have enlarged thyroids, and a patient in the hospital from her neighbourhood has goitre. The water at Dunstable is chalky. She attended the out-patient department for eight months for goitre, during which time all the usual remedies (ointments, liniments, \&e.) were studiously applied without diminution in the size of the swelling, but rather a slight increase. At her earnest solicitation she was admitted to the hospital to have the growth removed.

Tpon admission there was a tumour about the size of a large duck's ergr at the right side of the neck, extending from about the third ring of the trachea to the upper border of the thyroid cartilage, overlapped by the edge of the sterno-mastoid musele, yielding an indistinct sense of fluctuation. Also some thickening of the isthmus of the thyroid body, the whole moving with deglutition; at the same time with a sense of free movability in itself.

July 20 th, the patient being under an anæsthetic, I made an incision two inches and a half long over the tumour along the anterior edge of the sterno-mastoid, avoiding the external jugular vein, which was nearer the middle line than normal. The mastoid muscle being drawn outwards with retractor hooks, I proceeded to break down the adhesions with the point of the forefinger and handle of the knife, and experienced some difficulty, as the adhesions were tough and fibrous in character. Having broken through some larre branches from the superior thyroid artery, there was brisk bleeding till the ends were secured and tied with catgut ligatures. I now succeded in quite turning out the right lobe, and came to the isthmus, which was considerably enlarged. This I detachel from the trachea, getting well over to the left side, and secured it tightly in a catgut ligature before applying the knife. There was now hardly any bleeding, but a large cavity existed at the lower end, extending well down towards the clavicle and the large vessels of the neck externally. A horsehair drainage-tube was put in and the wound closely united with horsehair sutures; the carbolic spray, 1 in 20 , playing on the parts all through, all strict antiseptic precautions (Listerian) being observed during and after the operation.

For twenty-four hours the patient complained of difficulty in deglutition, which was her only trouble. Union throughout took place by first intention, without a drop of pus at any time, the drainage-tube and sutures being removed on the tenth day. Discharged from hospital on August 7th. Upon examining the growth after removal, it was found to be made up of a number of small cysts with thin walls, one larger than the rest at about its middle. Anteriorly it was irregularly conical and prominent, posteriorly flat, and very dark livid in colour; it measured three inches and a quarter in length and seven inches around its largest part.

Manchester-square, $\mathrm{w}$.

REPORT OF THE

\section{FIRST CASE OF OVARIOTOMY IN BARBADOES.}

\section{BY F. B. ARCHER, M.B., C.M.}

MARY B-_, aged nineteen years, single, was admitted into the General Hospital, Bridgetown, Barbadoes, on August 11th, 1879. She first noticed a swelling of her abdomen eighteen months ago, more conspicuous on the left side. Had occasionally a little pain, but not much. Catamenia always regular. Has lost flesh, but is fairly nourished.

On the 11th September, at 2 P.M., the patient was put under chloroform and an incision three inches and a half long was made, extending from above the pubes to a little below the umbilicus. A few slight adhesions were now broken down, a trocar inserted, and nineteen pints of fluid drawn off. The cyst (which weighed $4 \frac{1}{2} \mathrm{lb}$.) was removed, the pedicle (a small one) was secured with a silk ligature, cut short and returmed into the abdomen. The abdominal cavity was carefully sponged out with a solution of carbolic acid, all bleeding arrested, and the wound closed with nine silk sutures. Dry lint was placed over the wound, strapping and a bandage were applied, and the patient returned to her bed in the ward with the other patients. The operation lasted three-quarters of an hour. She vomited once only. In the evening the catheter was passed; she had ice to suck; one-sixth of a grain of morphia injected hypodermically; no vomiting; no pain. Temperature $101.4^{\circ} \mathrm{F}$

Sept. 12th.-Morning : Slept several hours last night. One pint of urine drawn off; one-sixth of a grain of morphia injected; nutrient enema given, and to be repeated every fourth hour. Evening : No pain, no sickness; seems to be getting on well. Temperature $100^{\circ}$

13th. - Allowed some milk and beef-tea by the mouth today; nutrient enemata stopped; passes water naturally. Temperature $1018^{\circ}$

14th. - Had a good night. Temperature $99^{\circ}$.

15th.-Wound dressed; very little discharge ; going on very well. Temperature normal.

16th. - Six stitches removed to-day; allowed to take soda water and brandy.

17th. - Wound dressed and the remaining stitches removed. Evening: Temperature $101^{\circ}$; pulse 120 . She says she feels very well.

18th. - Had a good night; an enema was administered, and the bowels freely opened; allowed chicken for dinner. Temperature $100^{\circ}$.

19th.-Temperature normal; going on well.

From this date her temperature continued normal. On the 28th the wound was healed, and she was allowed to get up. Her bowels only move after enema. She remained in hospital some time longer and rapidly regained her flesh and strength. We had no apparatus for carrying out the antiseptic treatment, or it would have been used. She remained in one of the ordinary wards of the hospital along with the other patients.

This is the first time the operation has ever been performed in this island.

Bridgetown, Barbadoes 